\title{
Anesthesia for Office Based Vocal Fold Injection
}

\author{
Han Su Kim (D) \\ Department of Otorhinolaryngology-Head \& Neck Surgery, College of Medicine, Ewha Womans University, Seoul, Korea \\ 외래 시행 성대주입술을 위한 마취 방법
}

김한수

이화여자대학교 의과대학 이비인후과학교실

Vocal fold injections are usually performed with a patient wake in an office under local anesthesia. For comfortable and safe office-based procedures, thorough anesthesia and premedication should be provided to the following three regions; nasal cavity, oropharynx, and larynx. Topical lidocaine is most widely used anesthetics on office based procedure. Lidocaine has a low to intermediate potency, 45 minutes to 60 minutes' duration of action, and onset of sufficient anesthesia within 90 seconds of topical administration. Tetracaine, prilocaine, ropivacaine, and bupivacaine also have been used in the office-based procedures. Nasal decongestant, oxymetazoline, is also used for widening nasal cavity by constriction of nasal mucosa. The amount of topical and local anesthetics used in vocal fold injection rarely exceeds toxic doses. The physician should know proper anesthesia techniques and must be familiar with the safe dose and complication of all anesthetics used.

Keywords Vocal cords; Anesthesia; Laryngoplasty; Injection; Lidocaine; Oxymetazoline.

\section{서 론}

성대주입술은 1911년 일측성 성대마비의 치료를 위해 Brünning에 의해 처음으로 보 고되었다. 초기에는 주입물의 특성, 주입 도구의 형태 등의 제한으로 인해 전신마취하에 경구강(transoral approach)으로 성대내주입술을 시행하였다. 그러나 최근 들어 인체 사 용의 안전성이 확보되고 유지 기간, 탄성 등이 다양한 성대 내 주입물이 상용화되어 이 전에 비해 가는 직경의 바늘을 이용하여 주입이 가능해지고, 내시경 장비의 발달로, 부 분 마취하에 다양한 경로를 통한 외래 술식(office-based procedure)으로 시행하는 것 이 일반적이 되었다.1)

외래에서 성대주입술을 시행할 때 후두내시경의 사용은 필수적이다. 후두내시경은 카 메라를 연결하여 모니터로 영상이 나오게 하여 술자, 조수 및 환자 모두가 술식의 과정 을 함께 공유할 수 있게 해준다. 일반적으로 후두내시경은 조수가 조작하기 때문에 화 면의 공유는 필수이며, 환자 또한 술식을 함께 보면서 발성, 숨참기 등 술자의 요구에 좀 더 적절하게 협조를 할 수가 있게 된다. 또한 모니터를 통한 확대된 영상 아래에서 주입 을 함으로써 좀 더 정확한 부위에 최적의 양을 주입할 수 있게 된다. 강직형 후두내시경 $\begin{array}{ll}\text { Received } & \text { October 23, } 2020 \\ \text { Revised } & \text { November 13, } 2020 \\ \text { Accepted } & \text { November 16, } 2020\end{array}$

Corresponding Author Han Su Kim, MD, PhD Department of OtorhinolaryngologyHead \& Neck Surgery, College of Medicine, Ewha Womans University, 1071 Ahnyangcheon-ro, Yangcheon-gu, Seoul 07985, Korea

Tel +82-2-2650-2686

Fax+82-2-2655-0983

E-mail sevent@ewha.ac.kr

ORCID iD

Han Su Kim (iD)

https://orcid.org/0000-0003-2239-0225

This is an Open Access article distributed under the terms of the Creative Commons Attribution Non-Commercial License (https://creativecommons.org/ licenses/by-nc/4.0) which permits unrestricted non-commercial use, distribution, and reproduction in any medium, provided the original work is properly cited. 
은 구강을 통해 삽입하며 굴곡형 후두내시경은 비강을 통해 삽입한 후 성문 바로 위에 위치시키게 된다. 따라서 내시경에 의한 구역 반사, 비강/구인두 불편감 등을 감소시키고 환자가 좀 더 편안한 상태에서 시술을 시행하기 위해서는 내시경이 통과하는 해부학적 통로 및 주입이 이루어지는 후두부에 적 절한 마취가 이루어져야 한다.

성대주입술 시행 시 마취 방법에 대해서 정립된 것은 없다. 몇몇 연구에서는 부분 마취제와 비점막 수축제를 '비강'에 사용하는 것이 오히려 시술 중 불편감을 증가시킬 뿐 이득이 없다고 보고하기도 한다..$^{2-5)}$ 하지만, '인두'와 '후두'에 아무런 전 처치를 시행하지 않고 성대내주입술을 시행하는 것은 환 자뿐 아니라 술자에게도 매우 힘들고 어려운 일이다. 적절하 고 안전한 마취는 환자의 구역 반사를 억제하고 편안한 협조 를 유도하여 빠르고 안전하게 성대주입술을 시행하는 데 가 장 중요한 첫걸음이다. 따라서 술자는 성대주입술 시 마취 방 법을 철저하게 익혀야 하며 사용하는 다양한 약제의 적절한 용량, 사용 방법, 부작용 대해서도 숙지해야 한다.

\section{본 론}

해 부

성대내주입술을 위한 마취에서 가장 중요한 것은 구역 반 사(gag reflex) 및 기침 반사(coughing reflex)를 억제하는 것 이다. 이를 위해 구역 반사가 일어나는 구인두, 기침 반사가 일 어나는 후두 및 내시경이 통과하는 비강에 적절한 마취가 시 행되어야 한다(Fig. 1).

\section{비강(Nasal cavity)}

비중격의 전방 $1 / 3$ 및 콧구멍에는 후각신경[olfactory nerve, cranial nerve $(\mathrm{CN}) 1]$ 의 전사골동분지(anterior ethmoidal nerve)가 분포한다. 비중격의 후방 $2 / 3$ 및 비갑개에는 삼차신 경(trigeminal nerve, CN5)의 상악가지로부터 나온 대구개 신경(greater palatine nerve)과 소구개신경(lesser palatine nerve)이 분포한다(Fig. 2). ${ }^{6}$

\section{구인두(Oropharynx)}

구역 반사는 구인두의 주요 감각 신경인 구인두신경 $\left(\mathrm{glos}^{-}\right.$ sopharyngeal nerve, CN9)에 의해 유발된다.7) 혀의 뒤쪽 $1 / 3$ 및, 후두계곡, 후두개의 전방부에는 구인두신경의 혀가지 (lingual branch)가 분포하며 구인두의 외측 및 뒤쪽 점막에 는 인두가지(pharyngeal branch)가 분포한다. 편도가지(tonsillar branch)는 편도선, 편도궁 및 연구개에 분포한다. ${ }^{8)}$

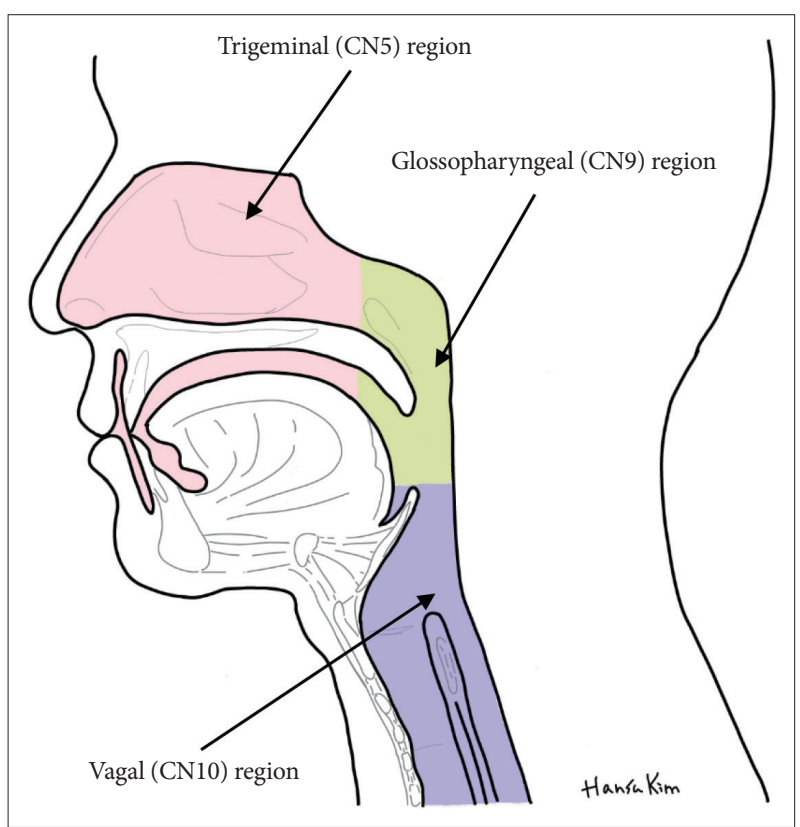

Fig. 1. Three regions for local anesthesia in vocal fold injection. The upper airway is divided into three regions depending on its major sensory innervations. $\mathrm{CN}$ : cranial nerve.

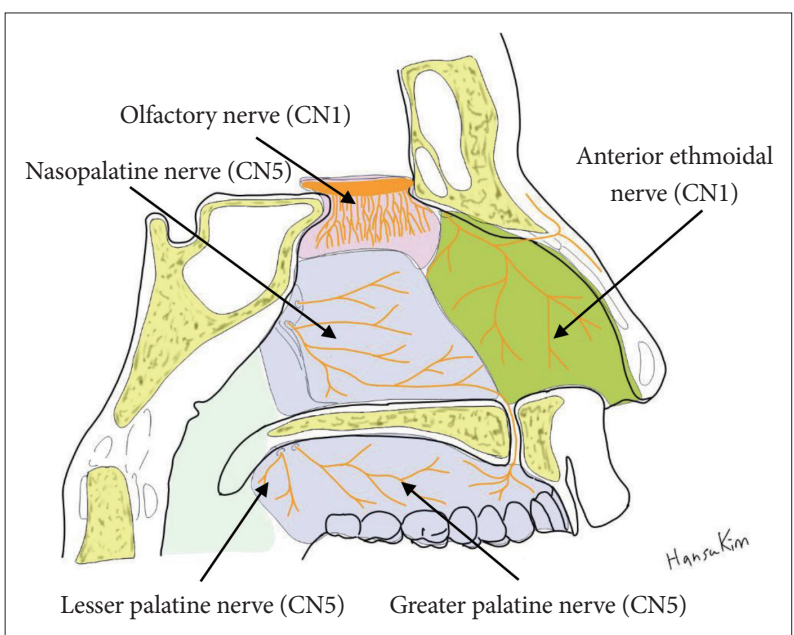

Fig. 2. Innervation of the nasal cavity. CN: cranial nerve.

\section{후두(Larynx)}

후두의 감각 및 운동신경은 미주신경(vagal nerve, CN10) 이 담당한다. 상후두신경(superior laryngeal nerve)의 내분 지(internal branch)가 성대 상부의 감각을 담당하며 외분지 (external branch)는 윤상갑상근에 분포하는 운동신경이다. 반회후두신경(recurrent laryngeal nerve)은 성대 및 성문 하부의 감각 및 윤상갑상근을 제외한 모든 내후두근육의 운 동을 담당한다. ${ }^{8}$

\section{약제(Medications)}

성대내주입술의 전처치에 가장 많이 사용되는 약제는 국소 
도포 마취제(topical anesthetics)와 점막 수축제(deconges$\operatorname{tant}$ )이다. 국소 도포 마취제는 구인두와 후두에 도포하여 구 역 및 기침 반사를 감소시키는 목적으로 사용된다. 점막 수 축제는 비강에 주로 사용되는데 비점막을 수축하여 비강을 확대시켜 내시경의 통과를 쉽게 해 줄 뿐만 아니라 통증 감 소에도 효과가 있다.9)

\section{마취제(Anesthetics)}

외래 시술을 위해 리도카인(lidocaine), 프릴로카인(prilocaine), 로피바카인(ropivacaine), 부피바카인(bupivacaine) 등 다양한 마취제가 상품화되어 있으며 몇몇 약제는 에피네 프린과 혼합된 형태로 판매되기 되기도 한다. 외국에서는 코 카인도 많이 사용하지만 국내에서는 사용이 불가하며, 리도 카인이 이비인후과에서는 가장 많이 사용되고 있다. 마취제 사용에 있어 가장 중요한 고려 사항은 마취제의 역가, 작용 시간, 발현 시간 및 안전 허용 용량 등이다. 역가(potency)는 마취제의 지방 용해성(lipid solubility)에 의해 결정된다.) 한 연구에 의하면 리도카인과 프릴로카인이 비강 마취에 있어서 부피바카인, 로피바카인에 비해 마취 유도가 빠르고 더 효과 적이라고 한다. ${ }^{10)}$ 스프레이 형태로는 리도카인과 테트라카인 이 가장 많이 사용된다. $2 \%$ 테트라카인과 $4 \%$ 리도카인을 비 교한 연구에 의하면 두 약제는 비슷한 효능을 가지고 있으나 고령 환자에서는 테트라카인이 부작용의 발현 정도가 낮은 것으로 보고하고 있다. ${ }^{3)}$

\section{리도카인(Lidocaine)}

리토카인은 중등도 이하의 역가를 가지고 있다. 주입 후 90 초 이내에 약효가 발현되며 약 45 60분 정도 유지된다. $1 \%$, $2 \%, 4 \%, 10 \%$ 등 다양한 농도의 약제를 임상 현장에서 사용 할 수 있는데, ${ }^{7}$ 성대내주입술의 경우 국내에서는 $100 \mathrm{mg} / \mathrm{mL}$ 의 $10 \%$ 리도카인 스프레이가 가장 많이 사용된다(Fig. 3). 리 도카인의 허용 용량은 ‘주사제’로 사용했을 시 성인의 경우 $4.5 \mathrm{mg} / \mathrm{kg}$ 이며 에피네프린이 포함된 경우 $7 \mathrm{mg} / \mathrm{kg}$ 으로서, ${ }^{11)}$ $70 \mathrm{~kg}$ 성인을 예로 들면 약 $300 \mathrm{mg}$ 정도의 리도카인을 투여 가능하다. $10 \%$ 리도카인 스프레이를 한 번 분무할 경우 약 $10 \mathrm{mg}$ 정도의 리도카인이 점막에 도포된다. 외래 시술 시 일 반적으로 2 3회 정도 도포를 하게 되므로 안전 허용 용량이 초과되는 경우는 드물다(Table 1).

\section{테트라카인(Tetracaine)}

테트라카인은 리도카인에 비해 높은 역가를 가지고 있으며 약 60 120분 정도의 약효 지속 시간을 가지고 있다.7) 특히 비강 마취에 있어서 리도카인에 비해 더 빠르게 마취가 유도

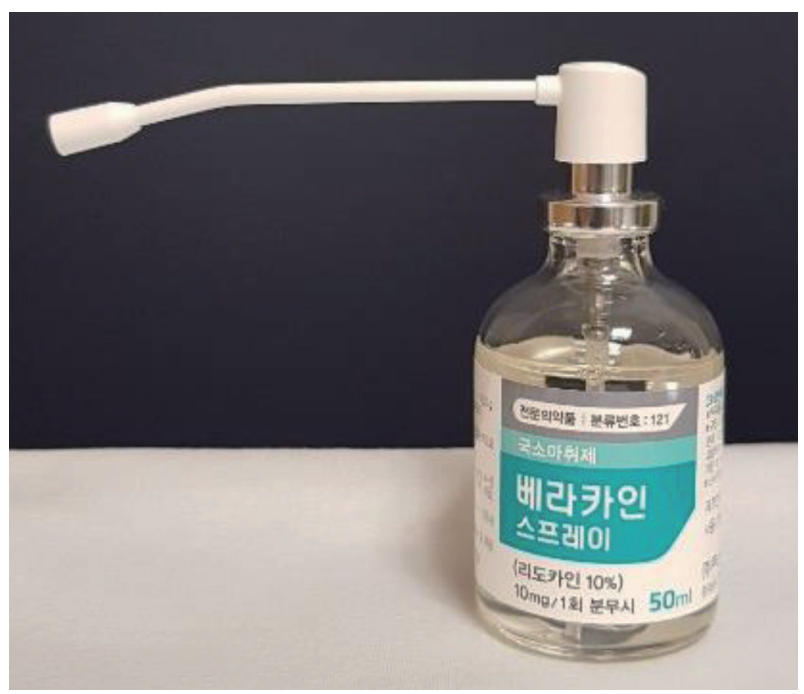

Fig. 3. 10\% lidocaine spray (Beracaine spray, Firson). It contains $100 \mathrm{mg} / \mathrm{mL}$ lidocaine. For anesthesia of the throat, larynx, and trachea, the safety dose of this lidocaine spray is up to $200 \mathrm{mg}$ (twenty times of spray).

Table 1. Recommended dosage of 'injectable' lidocaine

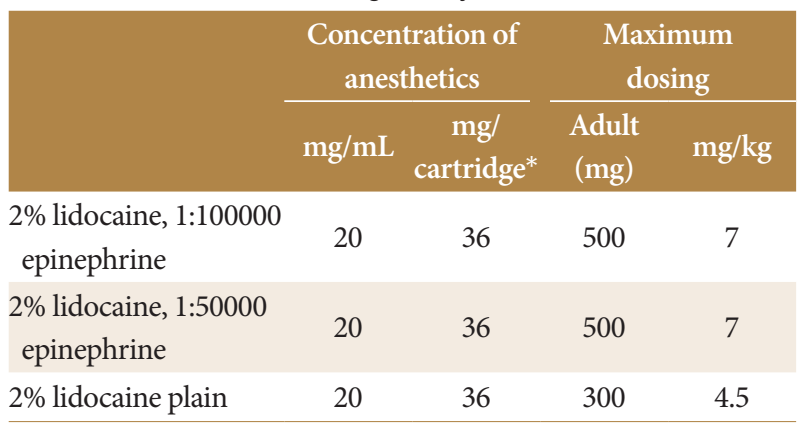

*All cartridges are assumed to contain approximately $1.8 \mathrm{~mL}$

될 뿐만 아니라 통증 조절에도 더 효과가 좋은 것으로 보고 되고 있다. ${ }^{12)}$ 국소 도포용으로 사용할 때 부작용은 많지 않 은 것으로 되어 있다. 이비인후과 점막 마취에는 $2 \% / \mathrm{mL}$ 농도 약제를 주로 사용하며 분무기(atomizer)를 이용해 1회 분무 시 약 0.1 0.2 mL 정도가 전달되도록 사용한다. ${ }^{7)}$

\section{점막 수축제(Decongestants)}

점막 수축제는 비강 점막을 수축시켜 비강을 확장하는 목 적으로 사용한다. 옥시메타졸린(oxymetazoline), 페닐에프린 (phenylephrine), 에피네프린(epinephrine), 코카인(cocaine) 등이 있으며 옥시메타졸린이 다른 약제들에 비해 혈압 상승, 빈맥 등의 부작용은 적으면서 효능은 우수하기 때문에 가장 많이 사용된다. ${ }^{13)}$ 또한 옥시메타졸린과 리도카인을 병용할 경우 내시경에 의한 통증 감소에 가장 효과적인 것으로 되어 있다. ${ }^{9}$

성인 및 6세 이상의 소아에서의 권장 용량은 $0.05 \%$ 옥시 
메타졸린으로서 양쪽 비강에 2 3회 분무를 하는 것이다. 옥 시메타졸린을 포함한 모든 점막 수축제는 혈압 상승, 빈맥 및 반응성 서맥 등의 부작용을 유발할 수 있으므로, ${ }^{13)}$ 고령 및 심혈관질환의 병력을 가지고 있는 환자에서의 사용 시에는 유의하여야 한다.

\section{분비물 억제제(Anti-secretion medications)}

콧물, 침 등의 분비액은 내시경의 시야을 방해할 뿐만 아니 라 마취제를 희석시키고 점막과 마취제 사이에 일종의 격막층 을 형성하여 약제의 효과를 감소시킨다. ${ }^{14)}$ 가장 많이 사용되 는 약제는 글라이코피롤레이트(glycopyrrolate)이며 이 외 아 트로핀(atropine), 스코폴라민(scopolamine) 등이 사용된다. 글라이코피롤레이트는 뇌혈관장벽을 통과하지 않기 때문에 중추신경계에 영향을 주지 않으며, 아트로핀에 비해 빈맥을 발현시키는 빈도가 적은 장점이 있다. 허용 용량은 $3 \sim 4 \mu \mathrm{g} / \mathrm{kg}$ 이며, 성인의 경우 일반적으로 $0.2 \mathrm{mg}$ 정도를 사용한다. 대부 분 근주로 투여하게 되며 시술하기 최소 15 분 전에 투여해야 효과가 있다. ${ }^{15)}$

\section{환자 준비 및 부위별 마취}

\section{환자 준비(Patient preparation)}

외래에서 시행하는 성대내주입술에서는 환자의 협조가 필 수적이다. 따라서 시술 전에 전체 과정에 대해 충분한 설명을 한 후 동의를 받아야 한다. 심전도, 산소포화도 등 모니터링 은 일반적으로 필요하지 않으며 이비인후과 진료 의자에 앉 거나 침대에 누운 자세에서 시행한다. 성대내주입술은 안전 하며 대부분 빨리 끝나기 때문에 말초 정맥 라인을 필수적으 로 확보할 필요는 없다. 다만 시술 과정 중에 아나필락시스에 의한 쇼크나 미주신경 반사성 실신(vasovagal syncope) 등이 발생할 수 있기 때문에 응급상황 대비용으로 확보를 할 수도 있다.

시술 중 실신이 발생하거나 구역, 발한, 두통, 이상감각 등의 증상을 환자가 호소할 경우에는 시술을 중단하고 환자를 앙 와위로 눕힌 후 심박수, 혈압 등을 확인한다. ${ }^{7)}$

\section{비강 마취(Nasal anesthesia)}

비강 마취에는 주사제 또는 신경 차단 등, 침습적인 마취 방법은 대부분 필요하지 않으며 도포 점막 마취로 충분하다. 점막 수축제를 마취제 도포 전에 분무함으로써 마취제의 전 신 흡수를 감소시킬 수 있으며 비강이 확장되어 내시경 삽입 시 통증 감소, 출혈 예방 등의 효과를 거둘 수 있다.구

일반적인 비강 마취 방법은 다음과 같다. 먼저 점막수축제
을 양측 비강에 분무한 후 점막 수축제와 마취제가 혼합된 솜(cotton pledget)을 비강에 삽입한다. 솜은 하비도(비강저) 에 하나를 위치하고 이후 그 위로 중비도, 상비도를 겨냥하여 하나씩 총 세 개를 삽입한다. 솜은 사용 전에 꼭 짜서 과도한 약물이 투여되지 않도록 하며 시술 5 10분 전에 삽입한 후 시술 직전에 바로 제거한다.

\section{인두 마취(Pharyngeal anesthesia)}

인두 마취는 마취제의 국소 분무만으로도 충분히 마취가 유도된다. 저자의 경우 상품화된 10\% 리도카인(Beracaine spray, Firson, Cheonan, Korea)을 주로 사용한다(Fig. 3). 설 압자를 이용하여 혀를 누른 후 연구개와 인두 후벽에 2 3번 분무한 후 바로 삼키게 하는 매우 간단한 방법이다. ${ }^{16}$

이 외 $4 \%$ 리도카인을 $3 \mathrm{~mL}$ 의 생리식염수에 섞은 후 네블 라이저를 이용하여 흡입시켜 마취를 유도할 수 있다. 네블라 이져 방법은 후두 마취와 동시에 시행할 수 있는 장점이 있 으나, 시간이 오래 걸리고 장비가 필요하며 환자에 따라서 오 히려 분비물 증가를 호소하는 단점이 있다.

\section{후두 마취(Laryngeal anesthesia)}

후두 마취에는 다양한 방법이 있는데 일반적으로 다음의 세 가지 방법이 많이 사용된다. 가장 간단하며 저자가 사용 하는 방법은 인두 마취에 사용하는 것과 동일한, 상품화된 $10 \%$ 리도카인 스프레이를 이용하는 방법이다. 이 제품은 용 기에 긴 분무기가 달려 있어서 별도의 장비가 없이 인두 및 후두 마취에 사용이 가능하다. 먼저 위에서 설명한 인두 마 취를 시행한 후에 환자에게 혀를 잡아당기게 하고 강직형 후 두내시경을 보면서 후두개와 성대 점막에 리도카인을 2 3회 분무한다. 분무 시 환자에게 / $/ \mathrm{e}$ 소리를 내게 하면 마취제가 마치 가글을 하는 것처럼 성대 점막에서 튕기면서 골고루 마 취가 되도록 할 수 있다(laryngeal gargle). 이후 숨을 쉬게 하 면 마취제가 자연스럽게 기도로 흡인이 되어 성대 하부의 마 취도 유도가 된다.

두 번째 방법은 연성 후두내시경의 working channel을 통 해 마취제를 투여하는 방법이다. 마취가 된 비강을 통해 연성 후두내시경을 삽입하여 성대 점막 바로 위에 위치시킨 후/e/ 발성을 하는 동안 1 2 mL의 $4 \%$ 리도카인을 직접 성대 점막 에 점적을 하여 마취를 유도한다. 이 경우 working channel 이 있는 연성 후두내시경이 필요하며 일반 내시경에 비해 직 경이 굵으므로 비강 삽입 시 좀 더 힘들 수 있으므로 이를 고 려해야 한다. ${ }^{16,17)}$

마지막 방법은 비강 마취처럼 마취제가 점적된 솜을 직접 후두부에 접촉시켜 마취를 하는 방법이다. $4 \%$ 리도카인을 
적신 솜을 후두 겸자로 잡은 후 경구강을 통해 삽입하여 후 두개, 성대 점막 등에 직접 접촉을 시켜서 마취를 한다. 이 방 법을 이용할 때에는 인두부의 마취를 사전에 철저히 하여서 구역 반사가 일어나지 않도록 해야 하며 마취 솜이 떨어지지 않도록 주의해야 한다.

\section{피부 마취(Skin anesthesia)}

윤상갑상막 또는 갑상설골막 등 경부 피부를 통해 주입을 시행할 경우, 주입 부위에 피부 마취를 하는 것이 필요하다. $1 \%$ 리도카인 또는 1:100000 에피네프린이 혼합된 $1 \%$ 리도 카인을 피하에 주사한다. 피하에 너무 많은 양의 마취제를 주사하면 성대주입술을 위한 해부학적 지표가 가려질 수 있 다. 비교적 시술이 간단하고 빨리 끝나므로 주사 부위 주변 에만 소량을 주입하도록 한다.

\section{기타 고려 사항}

성대주입술 시 사용하는 약제는 허용 용량 내에서 사용만 하면 일반적으로 매우 안전하다. ${ }^{18)}$ 국소 마취제에 알레르기 반응이 있는 경우는 매우 드물지만 사용하는 약제에 알레르 기 반응이 있는지 여부를 확인해야 한다. 대부분의 환자들이 마취제에 알레르기 반응이 있는지 여부를 잘 알지 못하며 몇몇의 경우는 수술 자체를 해본 적이 없다고 한다. 저자가 사용하는 팁은 이전에 마취 주사를 맞고 치과 치료를 받아 본 적이 있는지 물어보는 것이다. 도포 마취제에 의해서 간혹 이물감, 통증, 화끈거림, 이상한 맛, 구역, 연하장애 등의 증 상이 나타날 수 있다.7.9) 또한 마취제가 성문하부 및 기관에 도포되어 마취가 된 경우 환자는 숨쉬기 힘들다고 표현하기 도 하는데, 대부분 시간이 지나면 사라진다. ${ }^{3,12)}$ 시술이 종료 된 후 60 90분 동안은 흡인을 방지하기 위해서 구강 섭취를 제한하는 것이 좋다.

고혈압이나 관상동맥질환을 가지고 있는 환자에게는 점막 수축제 사용을 주의해야 한다. ${ }^{13)}$ 시술 도중 불안해하거나, 내 시경이 비인두 또는 하인두를 자극하면서 혈압 및 심박수가 상승할 수 있기 때문에 약제에 의한 반응과 감별을 해야 한다.

\section{결 론}

성대주입술은 일측성 성대마비의 보형물 주입, 스테로이드 주입 등 다양한 치료 목적으로 외래에서 많이 시행하고 있는 술식이다. 사용하는 마취제 및 점막 수축제 등의 약제의 허 용 용량, 작용 기전 및 부작용을 숙지하고 정확한 방법으로 마취를 시행한다면 환자가 편안한 상태에서 신속하고 안전하 게 술식을 시행할 수 있다.
중심 단어: 성대, 마취, 후두성형술, 주입, 리도카인, 옥시메타 졸린.

Acknowledgments

None.

Conflicts of Interest

The author has no financial conflicts of interest.

\section{REFERENCES}

1. Ballard DP, Abramowitz J, Sukato DC, Bentsianov B, Rosenfeld RM. Systematic review of voice outcomes for injection laryngoplasty performed under local vs general anesthesia. Otolaryngol Head Neck Surg 2018;159(4):608-14.

2. Frosh AC, Jayaraj S, Porter G, Almeyda J. Is local anaesthesia actually beneficial in flexible fibreoptic nasendoscopy? Clin Otolaryngol Allied Sci 1998;23(3):259-62.

3. Gaviola GC, Chen V, Chia SH. A prospective, randomized, doubleblind study comparing the efficacy of topical anesthetics in nasal endoscopy. Laryngoscope 2013;123(4):852-8.

4. Cain AJ, Murray DP, McClymont LG. The use of topical nasal anaesthesia before flexible nasendoscopy: a double-blind, randomized controlled trial comparing cophenylcaine with placebo. Clin Otolaryngol Allied Sci 2002;27(6):485-8.

5. Haytoğlu S, Kuran G, Muluk NB, Arıkan OK. Different anesthetic agents-soaked sinus packings on pain management after functional endoscopic sinus surgery: which is the most effective? Eur Arch Otorhinolaryngol 2016;273(7):1769-77.

6. Hornung DE. Nasal anatomy and the sense of smell. Adv Otorhinolaryngol 2006;63:1-22.

7. Wang SX, Simpson CB. Anesthesia for office procedures. Otolaryngol Clin North Am 2013;46(1):13-9.

8. Yoshida Y, Tanaka Y, Hirano M, Nakashima T. Sensory innervation of the pharynx and larynx. Am J Med 2000;108(4):51-61.

9. Şahin Mİ, Kökoğlu K, Güleç Ş, Ketenci İ, Ünlü Y. Premedication methods in nasal endoscopy: a prospective, randomized, double-blind study. Clin Exp Otorhinolaryngol 2017;10(2):158-63.

10. Gencer ZK, Özkiriş M, Gencer M, Saydam L. Comparison of ropivacaine, bupivacaine, prilocaine,andlidocaine in the management of pain and hemorrhage during nasal pack removal. Am J Rhinol Allergy 2013;27(5):423-5.

11. Cherobin ACFP, Tavares GT. Safety of local anesthetics. An Bras Dermatol 2020;95(1):82-90.

12. Bourolias C, Gkotsis A, Kontaxakis A, Tsoukarelis P. Lidocaine spray vs tetracaine solution for transnasal fiber-optic laryngoscopy. Am J Otolaryngol 2010;31(2):114-6.

13. Latham GJ, Jardine DS. Oxymetazoline and hypertensive crisis in a child: can we prevent it? Paediatr Anaesth 2013;23(10):952-6.

14. Prasanna D, Bhat S. Nasotracheal intubation: an overview. J Maxillofac Oral Surg 2014;13(4):366-72.

15. pie.med.utoronto.ca [Internet]. Toronto: University Health Network [cited 2020 Oct 23]. Available from: http://pie.med.utoronto.ca/BI/ index.htm.

16. McPartlin DW, Nouraei SAR, Tatla T, Howard DJ, Sandhu GS. How we do it: transnasal fibreoptic oesophagoscopy. Clin Otolaryngol 2005;30(6):547-50.

17. Verma SP, Smith ME, Dailey SH. Transnasal tracheoscopy. Laryngoscope 2012;122(6):1326-30.

18. Neal JM, Bernards CM, Butterworth JF, Di Gregorio G, Drasner K, Hejtmanek MR, et al. ASRA practice advisory on local anesthetic systemic toxicity. Reg Anesth Pain Med 2010;35(2):152-61. 